\title{
Análise de minicontratos de dólar futuro por média móvel exponencial com reinvestimento dos retornos e balanceamento dos riscos
}

\section{Livio Marcel Queji}

Iqueji@gmail.com

Universidade Estadual de Ponta Grossa (UEPG), Ponta Grossa, Paraná, Brasil.

Luiz Gustavo Tracz de Souza luizgustavotracz@hotmail.com

Universidade Estadual de Ponta Grossa (UEPG), Ponta Grossa, Paraná, Brasil.

\section{Ernani Barbosa Lepka} ernaniblepka@gmail.com

Universidade Estadual de Ponta Grossa (UEPG), Ponta Grossa, Paraná, Brasil.

Joselton José de Almeida Rocha joseltonrocha@gmail.com

Universidade Estadual de Ponta Grossa (UEPG), Ponta Grossa, Paraná, Brasil.

\section{Cesar Eduardo Abud Limas} cesar.adm.uepg@gmail.com Universidade Estadual de Ponta Grossa (UEPG), Ponta Grossa, Paraná, Brasil.

\begin{abstract}
RESUMO
O objetivo deste trabalho é apresentar uma estratégia operacional para se aplicar nos minicontratos de dólar futuro com a utilização da média móvel exponencial de 21 períodos no gráfico de renko com aplicação de técnicas de reinvestimento dos retornos e balanceamento do risco. Com isso, busca-se minimizar o valor do capital inicialmente aplicado, beneficiar-se da vantagem percebida no contrato futuro de dólar, utilizar um manejo de risco baseado no reinvestimento dos ganhos para potencializar os retornos, porém balanceando o tamanho das posições para minimizar as perdas quando as operações derem prejuízo, ou seja, nos momentos em que a estratégia não tenha um bom desempenho com a exposição ao risco diminui e quando a estratégia estiver apresentando bons resultados aumenta-se a posição buscando maiores retornos.
\end{abstract}

PALAVRAS-CHAVE: Dólar Futuro. Mercados Futuros. Manejo de Risco. 


\section{INTRODUÇÃO}

A motivação para a elaboração desse estudo surgiu num Grupo de Pesquisas em Mercado de Capitais do Departamento de Administração na Universidade Estadual de Ponta Grossa (UEPG) no estado do Paraná. Após um estudo minucioso das características do derivativo de dólar futuro, conhecido como minicontrato de dólar futuro, instrumento financeiro usado para a realização das operações de hedge cambial nas pequenas empresas estudadas organizou-se uma pesquisa com o interesse na realização de operações especulativas no minicontrato de dólar futuro.

Isso se explica pela natureza volátil do minicontrato de dólar futuro, que diariamente apresenta uma movimentação que proporciona várias oportunidades operacionais tanto na ponta comprada, quando se espera que o movimento seja de alta, quanto na ponta vendida, quando se espera que o movimento seja de baixa.

Somado a essa volatilidade diária, a alavancagem e as taxas operacionais reduzidas oferecidas pelas sociedades corretoras nos derivativos cambiais, tornam esse produto financeiro ainda mais atraente para a realização de operações especulativas, as operações conhecidas como day trade.

Pelo fato de haver um cuidado com a empolgação e o ímpeto dos jovens estudantes diante das oportunidades de ganhos alavancados, além da exposição a diversos conteúdos fantasiosos com a promessa de ganhos que são em sua maioria ilusórios, disponíveis eletronicamente e nas redes sociais, decidiu-se elaborar uma estratégia operacional que unisse simplicidade, objetividade e expectativa matemática positiva, ou seja, realização de um manejo de risco adequado sob o capital empregado. Pensando desta maneira tem-se a intenção de tornar a alavancagem oferecida pelas corretoras em uma vantagem, e não em um obstáculo ao sucesso da estratégia.

Vince (2007) argumenta que mais importante que o índice de acerto de qualquer estratégia elaborada para aplicação no mercado financeiro é que esta estratégia contemple uma expectativa matemática positiva e um manejo de posição que possibilite o reinvestimento adequado dos ganhos, proporcionando ganhos crescentes.

Além de uma estratégia bem elaborada, atendendo os pontos levantados anteriormente, é necessário ainda levar em consideração questões comportamentais. Douglas (2015) em sua obra "Trading: atitude mental do trade de sucesso" comenta que o primeiro passo para se ganhar confiança e disciplina na realização de suas operações no mercado financeiro, deve-se compreender e principalmente aceitar a realidade psicológica dos mercados, pois só assim será possível alcançar sucesso na gestão dos riscos envolvidos na atividade de operar especulativamente os mercados financeiros.

Para se atingir o objetivo acima delineado, serão inicialmente definidos os procedimentos metodológicos norteadores do estudo. Na sequência serão trazidos aspectos conceituais do mercado de futuros, derivativos financeiros, derivativo de dólar futuro, análise gráfica e utilização de médias móveis exponenciais. Para finalizar o estudo será descrita a estratégia operacional, a forma que se fará o manejo de risco e a apresentação dos resultados obtidos com a aplicação da estratégia. 


\section{PROCEDIMENTOS METODOLÓGICOS}

Para se alcançar o objetivo proposto e nortear este estudo na cientificidade foram utilizados os seguintes métodos de pesquisa.

Quanto a natureza trata-se de uma pesquisa aplicada. Deste modo Silva (2001) comenta que a pesquisa aplicada tem como motivação básica a solução de problemas concretos ou de aplicação prática que é justamente o que se busca atingir com a elaboração do presente estudo.

Em se tratando de seus objetivos a pesquisa classifica-se em exploratória. Nessa perspectiva Gil (2007) conceitua que a pesquisa nessa modalidade deve explorar a realidade, buscando conhecimento, para que em seguida possa descrevê-la com riqueza de detalhes. O cunho exploratório é observado com clareza no presente estudo e isso poderá ser comprovado no decorrer das páginas.

A pesquisa classifica-se como qualitativa do ponto de vista da forma de abordagem do problema, considerando que não podemos traduzir em números um vínculo entre o mundo objetivo e a subjetividade do sujeito, portanto não requer uso de métodos e técnicas estatísticas ou determinação de amostragens significativas (RICHARDSON, 2007).

Do ponto de vista da forma de abordagem do problema a modalidade de pesquisa classifica-se como quali-quantitativa, sendo que "[...] interpreta as informações quantitativas por meio de símbolos numéricos e os dados qualitativos mediante a observação, a interação participativa e a interpretação do discurso dos sujeitos" (KNECHTEL, 2014, p. 106).

Com a utilização de material já publicado, os procedimentos técnicos assumirão a classificação de pesquisa bibliográfica. Também envolve aspecto de estudo de caso, envolvendo o estudo aprofundado de um objeto que permitirá seu detalhado conhecimento (SILVA, 2001).

\section{DÓLAR FUTURO}

O mercado de contratos futuros tem importante relevância para o desenvolvimento econômico. Nele existe a possibilidade de estruturar operações de posições que envolvam ativos reais, especular sobre o futuro de determinado ativo e arbitrar seus preços e valores. A estruturação, de forma acessível e rápida, de operações de proteção (hedge) sobre diversos ativos minimiza a incerteza a que estão expostos os agentes econômicos (ADAM et al., 2017).

A estruturação dessas operações acontece por meio de contratos acordados por duas partes que se comprometem a comprar o ativo no presente e vender esse mesmo ativo a determinado preço no futuro (LIMA FILHO, 2017). Por exemplo, se na data de vencimento do contrato futuro o dólar à vista estiver valendo mais que o preço acertado, ganha a parte compradora (visto que comprou por um preço menor que o preço pago na data de acordo do contrato) e a parte vendedora perde, e vice-versa (GARCIA, 1997).

Os contratos futuros possuem um padrão de negociação pela bolsa de valores, envolvendo a quantidade, o valor da negociação, data de vencimento e forma de cotação. O valor para negociação desse derivativo é de US\$ 10 mil para 
contratos fracionados (mini dólar) e US\$ 250 mil para a negociação padrão (dólar cheio). Ao negociar o dólar futuro, negocia-se a taxa de câmbio de reais por dólar comercial, sendo o tamanho padrão do contrato o valor de US\$50.000,00 com um lote mínimo de negociação de 5 contratos - efetivamente negocia-se a compra/venda de US\$250.000,00 (GARCIA, 1997).

Não existe uma negociação efetiva de dólares no mercado de dólar futuro, visto que as operações são liquidadas em reais e não há movimentação de divisas ou contratos de câmbio. O conceito mais amplo aponta que ao negociar o dólar futuro, negocia-se o valor em reais da variação de determinada quantidade de dólares em relação à moeda brasileira (ROSSI, 2015).

No mercado futuro do dólar, os mecanismos de alavancagem e a maior liquidez na negociação possibilitaram uma maior facilidade de entrada de novos agentes que antes não atuavam no mercado do dólar. Segundo Rossi (2014), os agentes que atuam no mercado futuro são as corretoras, o Governo, os bancos e as pessoas jurídicas.

O contrato futuro do dólar é uma importante ferramenta para os agentes econômicos, visto que com ele torna-se possível a diminuição dos riscos relativos a variação da taxa de câmbio no comércio internacional (ADAM et al., 2017). Como na grande maioria dos mercados, no mercado futuro do dólar os participantes dividem-se em vendedores, compradores e intermediários, sendo os vendedores as empresas exportadoras, os compradores as empresas que precisam importar divisas e os intermediários as corretoras e os bancos. Em meio a essa dinâmica há também o Governo que intervém de acordo com a sua política e os especuladores que negociam contratos com o objetivo de comprar a um preço baixo para vender a um preço mais alto ou vice-versa (LIMA FILHO, 2017).

Em síntese, o contrato futuro de dólar constitui-se numa importante ferramenta que recebe interações de quase todos os agentes que atuam no mercado. Pelo fato de ser um contrato futuro, abre-se espaço para a realização de inúmeras operações estruturadas, objetivando diminuir o risco que os agentes econômicos se expõem nacional e internacionalmente.

\section{ANÁLISE TÉCNICA E O GRÁFICO RENKO}

A eficiência dos mercados é um dos assuntos discutidos por acadêmicos e pesquisadores que mais gera controvérsias entre os economistas. A análise técnica, uma das estratégias disponíveis para uso dos agentes de mercado, utiliza-se de informações passadas sobre os preços para definir as decisões de investimentos futuros (SAFFI, 2003). Diversos autores fazem uso dessa estratégia (FAMA e BLUME, 1966; SWEENEY, 1988), buscando evidências sobre sua performance superior no alcance de resultados e retornos em relação à estratégia de "comprar e esperar". Estas evidências resultariam no desprezo da eficiência sob a forma fraca, resultados encontrados mesmo depois de serem considerados os custos de transação.

As principais características da análise técnica são (NELOGICA, 2019):

a) Análise de dados gerados por transações como volume e preço;

b) Uso de gráficos na busca por padrões; 
c) Visualização dos componentes emocionais presentes no mercado;

d) Análise de tendências e determinação de alvos (até onde os preços irão chegar).

A análise técnica de investimentos tem como base o uso de informações passadas dos preços de um ativo com objetivo de gerar sinais de compra e venda (SAFFI, 2003). Ela pode ser subdividida em dois tipos básicos de estratégias: análise computadorizada e análise gráfica.

A análise computadorizada utiliza funções dos preços passados (indicadores técnicos) nas decisões de investimentos. Estes indicadores fazem a tentativa de expressar um suposto consenso do mercado com relação ao preço do ativo no futuro, utilizando para isso informações correntes com o volume e preços de fechamento, máximo ou mínimo. Devido a facilidade de cálculo desses indicadores, é possível estabelecer objetivamente critérios de compra e venda de um ativo, sendo extremamente simples a sua implementação computacional (LO et al., 2000). Esta análise não faz parte do escopo de estudo deste trabalho e, por este motivo, não será aprofundada.

A análise gráfica começou a ser usada no início do século XX com os trabalhos de Charles Dow que junto com Edward D. Jones publicavam um informativo sobre finanças que mais tarde viria a se transformar no "The Wall Street Journal". Por meio do jornal, Dow mostrava suas observações e análises sobre o comportamento do mercado. Algum tempo depois o conjunto desses textos e informativos viria a se tornar o que pode ser considerado como o início da análise técnica moderna: a Teoria de Dow. Esse tipo de análise técnica utiliza gráficos como principal ferramenta de análise na determinação do melhor momento (e preço) para comprar e vender ativos (NELOGICA, 2019).

O Gráfico Renko, teve sua criação no Japão e tem como principal premissa considerar o tempo e o volume de negócios para trabalhar exclusivamente com as variações de preço daquele determinado ativo. Trata-se de um gráfico atemporal, ou seja, as barras representam apenas a variação do preço do ativo, sem importar o tempo e o volume negociados (NELOGICA, 2019).

O Gráfico Renko compõe-se de "caixas" (ou "tijolos"), em que a formação de novas caixas depende do ativo atingir determinada variação em relação à mínima ou máxima da caixa anterior. Nesse sentido, independentemente do tempo, nenhuma caixa será criada se o ativo andar para o lado, ou seja, as pequenas variações de preço são ignoradas. Isso tem como vantagem menores ruídos que levam a maior facilidade para identificar suportes, resistências e principalmente a tendência do ativo. Isso faz com que o gráfico seja conhecido como um "gráfico limpo" (BOLSA, 2019).

\section{MÉDIA MÓVEL EXPONENCIAL}

Elder (2006, p.96), ressalta que "as médias móveis estão entre as ferramentas mais antigas, mais simples e mais úteis para os operadores. Nós as plotamos como linhas num gráfico de preços, em que cada um dos pontos reflete o mais recente cálculo da média dos preços".

A média móvel clássica, mais utilizada, também conhecida como Média Móvel Aritmética (MMA), é apresentada na fórmula (1): 
Onde $\mathrm{Pn}$ é qualquer quantidade de períodos que se queira calcular.

Segundo Debastina (2008, p. 88), "as barras de preço de um gráfico de determinado ativo se localizam sempre acima da linha de média móvel quando o papel está em tendência de alta, e sempre abaixo dessa linha quando o papel está em tendência de baixa".

Wolwacz (2010) ressalta que o problema ao utilizar a média móvel aritmética é quando ocorre um movimento forte de alta ou de baixa, podendo o traço da média móvel sofrer certa distorção, tanto na entrada desse preço discrepante quanto na sua saída do espaço temporal abrangido pela fórmula. Na entrada, momento em que os preços oferecem um salto grande, a média móvel se comportará de forma mais branda, porque sofre influência do passado, na mesma proporção do presente. Na saída, momento em que os preços podem não apresentar grande discrepância, ou até apresentar movimento em sentido contrário, a linha pode saltar com mais intensidade, pois a saída do preço antigo vai influenciar o cálculo na mesma proporção daquele que está entrando agora. Para minimizar tal efeito, no presente estudo, usaremos a média móvel exponencial.

A média móvel exponencial possui um cálculo mais complexo, pois procura dar relevância aos valores mais recentes no tempo. O cálculo pode seguir diversas linhas, mas o mais utilizado na análise gráfica é a apresentada na fórmula (2):

$$
\operatorname{MME}(\mathbf{n})=(\operatorname{Preço~} \mathbf{X})+(\operatorname{MME}(\text { anterior }) \times(1-K)
$$

Onde $K=2 / n+1$

O resultado dessa fórmula é uma linha mais próxima dos preços de fechamento, que reage rapidamente aos seus movimentos, sendo mais branda em movimentos laterais e menos propensa a sinais falsos durante as tendências, é tida como um elemento de maior precisão.

\section{DESCRIÇÃO DA ESTRATÉGIA}

A estratégia utilizada para a realização das entradas e saídas nas operações leva em consideração o gráfico de renko na configuração de $3 r$ onde cada caixa do renko equivale a um ponto de dólar, ou dois ticks.

Para balizar as operações em compra de minicontratos de dólar futuro ou venda de minicontratos de dólar futuro será utilizado a média móvel exponencial de 21 períodos. Assim, quando os preços estiverem trabalhando acima da média móvel exponencial de 21 irá se buscar sinais na ponta compradora e se os preços estiverem cotando abaixo da média móvel exponencial de 21 se buscará por sinais na ponta vendedora. 
Figura 1 - Sinal de entrada na ponta compradora

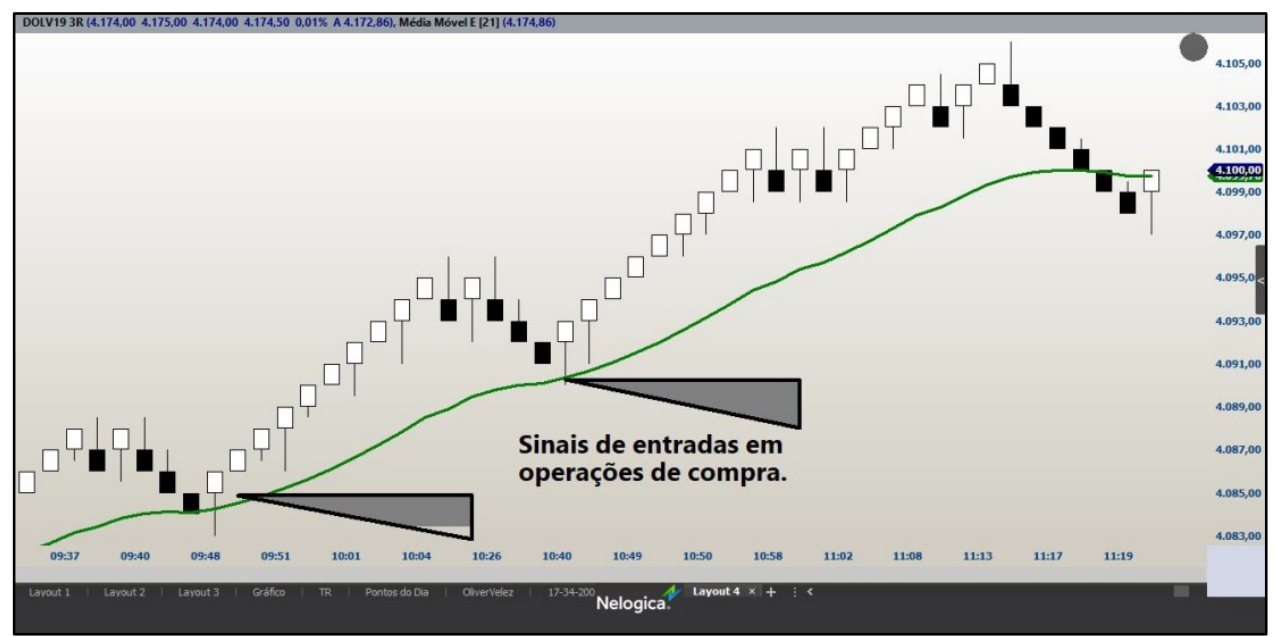

Fonte: Autoria Própria (2019)

Na Figura 1 observam-se os sinais de entrada em operações na ponta compradora. Os renkos pretos referem-se a movimentos de baixa e os renkos brancos referem-se a movimentos de alta. Desta forma, quando o renko sai da condição de baixa para a condição de alta, tem-se um sinal, no rompimento da máxima do primeiro renko de alta após um renko anterior de baixa, e o preço de entrada estando acima da média móvel exponencial de 21 pontos, sendo que assim a entrada pode ser validada.

Coloca-se o chamado stop loss, um tick abaixo da mínima do renko de entrada, o stop loss refere-se ao ponto que se encerra a operação no prejuízo previsto e se reconhece a perda, essa perda no caso do renko na configuração $3 R$ será de 3 pontos de dólar futuro.

Já o stop gain que se refere ao ponto de saída da operação com a realização do lucro será colocado 6 pontos de dólar futuro acima da entrada. Tendo desta forma uma relação risco/ganho de 2 para 1.

Figura 2 - Sinal de entrada na ponta vendedora

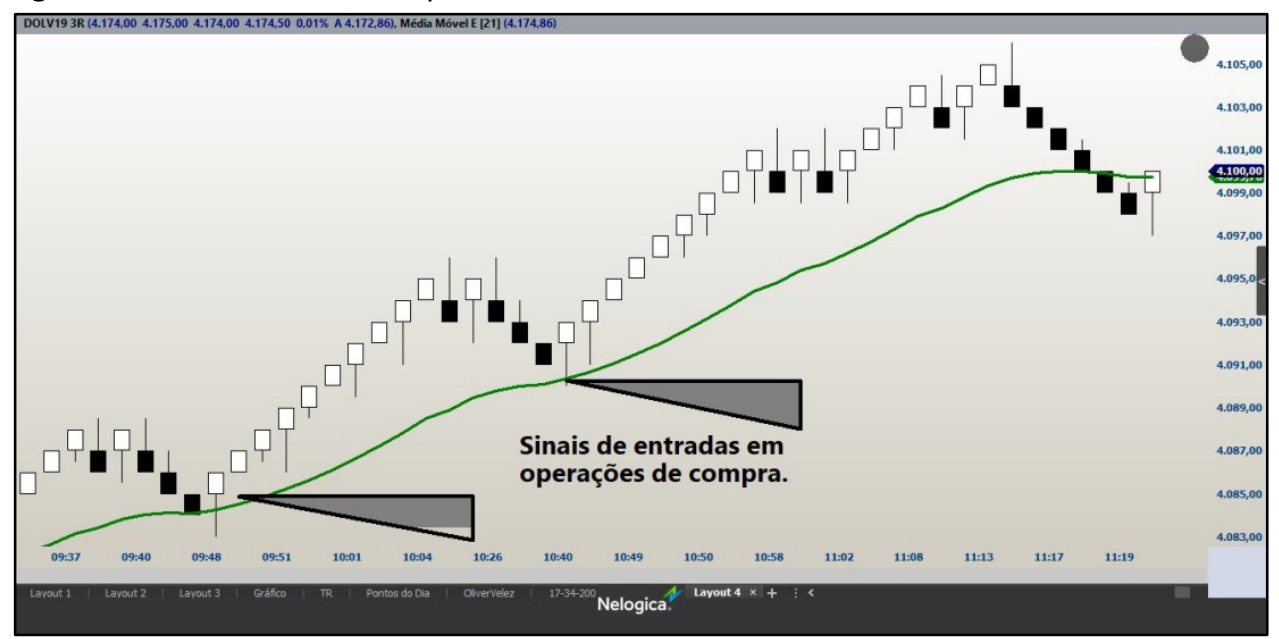

Fonte: Autoria Própria (2019) 
A figura 2 ilustra o sinal de entrada na ponta vendedora, agora os preços estão cotando abaixo da média móvel de 21 períodos e quando o primeiro renko de baixa (preto) aparece após um renko de alta (branco) é validada a entrada na ponta vendida. Aqui cabe uma ressalva, visto que as operações vendidas no mercado financeiro fogem da lógica das atividades comerciais onde não se pode vender o que não se possui. Contudo, no mercado de futuros é permitido vender primeiro e recomprar mais barato depois, lucrando a diferença.

$\mathrm{Na}$ operação vendida o stop loss (operação encerrada no prejuízo) também seria de 3 pontos e o stop gain (operação encerrada no lucro) de 6 pontos.

Na sequência do estudo serão descritos os detalhes envolvendo a execução prática da estratégia.

\section{PLANO DE TRADER E MANEJO DE RISCO}

Como em qualquer outra atividade empresarial, para que se tenha sucesso na aplicação prática da estratégia operacional é necessário planejamento prévio e a definição de regras operacionais claras e objetivas, que sustentem a disciplina e racionalidade do trader durante o pregão, não deixando fatores emocionais interferirem na execução do operacional previamente definido.

Douglas (2015) afirma que estabelecer regras faz todo o sentido, ainda mais em uma atividade que envolve recursos financeiros, porém a motivação de criar parâmetros e regras muitas vezes é vencida, pelo simples fato de que a maior parte de nossas vidas tentamos fugir delas. Segundo Douglas (2015) ainda, é preciso uma boa dose de emoções negativas para que se defina e cumpra um planejamento operacional organizado.

Visto isso e buscando uma gestão financeira prudente é que serão descritas as regras a serem seguidas na execução da estratégia proposta no estudo.

Primeiramente deve-se definir o produto que será o instrumento financeiro negociado para se atingir o objetivo proposto pelo trabalho, que é o minicontrato de dólar futuro. Um minicontrato de dólar futuro representa U\$10.000,00 e seu código de negociação é o WDO, seguido pela letra que representa o mês de vencimento do contrato e o ano vigente.

Um exemplo seria o WDOV19 que representa o código do minicontrato de dólar futuro referente ao mês de setembro de 2019. A troca de contratos ocorre no último dia útil de cada mês, onde encerra-se um contrato e inicia-se o novo contrato, conhecido como "dia de rolagem dos contratos".

A cotação do WDO segue o mesmo formato do contrato padrão de dólar futuro o DOL. Que seria pegar a multiplicação da cotação do Dólar Comercial por mil. Desta forma, o DOL e o WDO referentes ao valor do Dólar Comercial cotado em $R \$ 4,10$ seria de $R \$ 4.100,00$. A mínima variação nesse modelo de cotação do dólar futuro ocorre de $R \$ 0,50$ em $R \$ 0,50$. Assim temos, uma sequência de cotações do WDO seguindo esse formato: $R \$ 4.100,00$ - R\$ 4.100,50 - R\$ $4.101,00$ e $\mathrm{R} \$ 4.100,50$. A mínima variação é de $\mathrm{R} \$ 0,50$ e é conhecida como "um tick", já a variação de $R \$ 1,00$ que equivale a dois ticks é conhecida como 1 ponto de dólar futuro. 
O uso de um exemplo tornará mais fácil o entendimento do funcionamento e da dinâmica do WDO. Supondo que comprássemos um contrato de WDO na cotação de $R \$ 4.103,00$ e vendêssemos a $R \$ 4.103,50$ teríamos ganho um tick de WDO, que resultaria em um valor financeiro de $\mathrm{R} \$ 5,00$. Agora, se a operação fosse a compra de um WDO a $\mathrm{R} \$ 4.103,00$ com venda a $\mathrm{R} \$ 4.105,00$ teríamos um ganho de quatro ticks ou dois pontos de dólar futuro, o que resultaria em um ganho de $\mathrm{R} \$ 20,00$.

O capital inicialmente alocado para a execução da estratégia será de R\$ $1.500,00$, isso considerado o início com apenas um minicontrato de dólar futuro (WDO), com margem de garantia exigida pela corretora utilizada para as operações de $R \$ 80,00$ por minicontrato de dólar.

O horário definido para a execução da estratégia será das 9:00 da manhã que se refere ao horário de abertura do mercado de dólar futuro até as 12:00 horas. Esse horário foi definido simplesmente pela disposição de tempo dos acadêmicos envolvidos na pesquisa. Assim, ao meio dia encerram-se todas as operações independente do resultado.

O "stop loss" (encerramento da operação no prejuízo) por operação é de -3 pontos de dólar, utilizando-se um minicontrato de dólar futuro, isso equivale a $\mathrm{R} \$$ $-30,00$ e com dois minicontratos de dólar futuro, seria de $\mathrm{R} \$-60,00$ e assim por diante.

3 é o número máximo de "stop loss" diário, ou seja, -9 pontos de dólar futuro, que equivale a $\mathrm{R} \$-90,00$ de prejuízo por dia, mais os custos de corretagem e taxas da bolsa de valores. Assim, um dia ruim da estratégia, o prejuízo será de no máximo -9 pontos de dólar futuro multiplicado pelo número tamanho da posição em minicontratos que estiverem sendo operados na ocasião. O "stop gain" (encerramento da operação no lucro) será de 6 pontos por operação e de 12 pontos no dia, atingindo-se os 12 pontos diários encerra-se o operacional diário.

O manejo de posição foi a parte do trabalho que exigiu maior estudo, pois como argumenta Vince (2006) o reinvestimento dos ganhos pode alavancar os resultados de forma exponencial, porém nos períodos em que a estratégia não apresente consistência, as perdas podem consumir boa parte dos ganhos já obtidos, desencorajando a realização do reinvestimento dos retornos. Porém Vince (2007) comenta que nos períodos de perdas, deve-se reduzir as posições, reduzindo por consequência o risco por operação, minimizando assim as perdas globais da estratégia.

O presente estudo adotou a tabela abaixo para a realização do manejo de posição, assim a partir do capital inicial de $\mathrm{R} \$ 1.500,00$ a cada 36 pontos de minicontrato de dólar futuro acumulado adiciona-se um novo minicontrato, passando assim da fase 1, para a fase 2 . Se em virtude, de dias perdedores, o saldo baixar, volta-se a fase anterior. Desta maneira, se estivéssemos com uma posição de 5 minicontratos é porque o saldo acumulado chegou a $\mathrm{R} \$ 5.100,00$, porém se o saldo ficar abaixo deste valor, reduz-se imediatamente a posição para 4 minicontratos voltando para fase anterior. 
Tabela 1 - Fases do manejo de posição

$\begin{array}{ccc}\text { Nivel de risco } & \text { Numero de contratos } & \text { Saldo da Fase } \\ \text { Fase } 1 & 1 & R \$ 1,500.00 \text { a } R \$ 1.860,00 \\ \text { Fase } 2 & 2 & R \$ 1.860,00 \text { a } R \$ 2.580,00 \\ \text { Fase } 3 & 3 & R \$ 2.580,00 \text { a } R \$ 3.660,00 \\ \text { Fase } 4 & 4 & R \$ 3.660,00 \text { a } R \$ 5.100,00 \\ \text { Fase } 5 & 5 & R \$ 5.100,00 \text { a } R \$ 6.900,00 \\ \text { Fase } 6 & 6 & R \$ 6.900,00 \text { a } R \$ 9.060,00 \\ \text { Fase } 7 & 7 & R \$ 9.060,00 \text { a } R \$ 11.580,00 \\ \text { Fase } 8 & 8 & R \$ 11.580,00 \text { a } R \$ 14.460,00 \\ \text { Fase } 9 & 9 & R \$ 14.460,00 \text { a } R \$ 17.700,00 \\ \text { Fase } 10 & 10 & R \$ 17.700,00 \text { a } R \$ 21.300,00\end{array}$

Fonte: Autoria própria (2019)

A figura abaixo refere-se a uma nota de corretagem de compra e venda de um minicontrato de dólar futuro onde podemos observar os custos incorridos pela realização da operação. Essa única operação foi realizada por um dos membros da equipe de pesquisa, justamente para essa finalidade de observação dos custos na negociação de um único minicontrato de dólar futuro.

Figura 3 - Nota de corretagem de uma operação de compra e venda de WDO

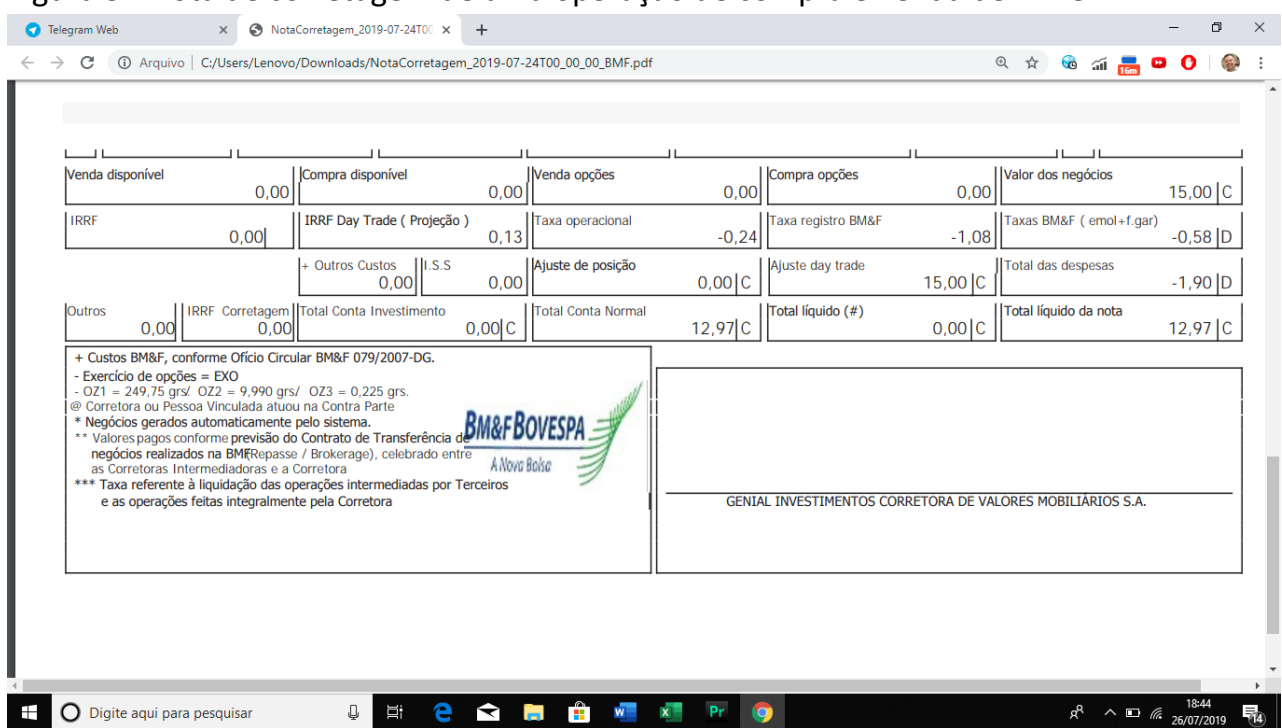

Nesta operação foi ganho 1,5 pontos de dólar, ou seja 3 ticks, o que resultou em um valor bruto de $\mathrm{R} \$ 15,00$, porém se fosse ganho 10 pontos de mini dólar futuro, fecharia em um ganho bruto de $\mathrm{R} \$ 100,00$ e os custos pela operação de entrada e saída seriam os mesmos.

$\mathrm{Na}$ nota temos $\mathrm{R} \$ 0,24$ de taxa operacional, referente a $\mathrm{R} \$ 0,12$ da corretagem de compra do WDO e R\$ 0,12 da corretagem da venda. A taxa de registro $B M \& F$ ficou em $R \$ 1,08, R \$ 0,54$ da compra e $R \$ 0,54$ da venda. Os emolumentos da BM\&F da operação realizada totalizaram $\mathrm{R} \$ 0,58$. E o Imposto de Renda que aparece na nota de corretagem no valor projetado de $R \$ 0,13$, refere-se a operação "day trade". Para a realização de 1 operação com um 
minicontrato de dólar futuro os custos totalizam $\mathrm{R} \$ 1,90$ por contrato e por operação.

Na sequência iremos descrever os resultados da aplicação da estratégia do início de agosto até o dia 23 de setembro, data determinada para o encerramento do estudo.

\section{RESULTADOS E CONCLUSÃO}

Dentro dos parâmetros descritos anteriormente foram realizadas as operações no mês de agosto, as quais podemos observar na tabela abaixo. Iniciou-se o mês na fase 1 com $R \$ 1.500,00$ em conta e no dia 30 de agosto encerrou-se o mês com um financeiro de $R \$ 4.608,00$ iniciando o mês de setembro na fase 4.

Tabela 1 - Resultado estratégia mês de agosto

\begin{tabular}{|c|c|c|c|c|c|c|c|}
\hline Data & Fase & Operações & Contratos & Pontos & Resultado & Resultado Líq. & SALDO \\
\hline 01 de Agosto & 1 & 3 & 1 & 12 & $\mathrm{R} \$ 120,00$ & $\mathrm{R} \$ 84,30$ & $\mathrm{R} \$ 1.584,30$ \\
\hline 02 de Agosto & 1 & 5 & 1 & 12 & $\mathrm{R} \$ 120,00$ & $\mathrm{R} \$ 110,50$ & $\mathrm{R} \$ 1.694,80$ \\
\hline 05 de Agosto & 1 & 3 & 1 & -9 & $-R \$ 90,00$ & $-\mathrm{R} \$(95,70)$ & $\mathrm{R} \$ 1.599,10$ \\
\hline 6 de Agosto & 1 & 5 & 1 & 15 & $\mathrm{R} \$ 150,00$ & $\mathrm{R} \$ 140,50$ & $\mathrm{R} \$ 1.739,60$ \\
\hline 7 de Agosto & 1 & 2 & 1 & 12 & $\mathrm{R} \$ 120,00$ & $\mathrm{R} \$ 116,20$ & $\mathrm{R} \$ 1.855,80$ \\
\hline 8 de Agosto & 1 & 6 & 1 & 15 & $\mathrm{R} \$ 150,00$ & $\mathrm{R} \$ 138,60$ & $\mathrm{R} \$ 1.994,40$ \\
\hline 9 de Agosto & 2 & 4 & 2 & 9 & $\mathrm{R} \$ 180,00$ & $\mathrm{R} \$ 164,80$ & $\mathrm{R} \$ 2.159,20$ \\
\hline 12 de Agosto & 2 & 7 & 2 & 3 & $R \$ 60,00$ & $R \$ 33,40$ & $\mathrm{R} \$ 2.192,60$ \\
\hline 13 de Agosto & 2 & 2 & 2 & 15 & $\mathrm{R} \$ 300,00$ & $\mathrm{R} \$ 292,40$ & $\mathrm{R} \$ 2.485,00$ \\
\hline 14 de Agosto & 2 & 3 & 2 & 15 & $\mathrm{R} \$ 300,00$ & $\mathrm{R} \$ 288,60$ & $\mathrm{R} \$ 2.773,60$ \\
\hline 15 de Agosto & 3 & 2 & 3 & 12 & $\mathrm{R} \$ 360,00$ & $\mathrm{R} \$ 348,60$ & $R \$ 3.122,20$ \\
\hline 16 de Agosto & 3 & 4 & 3 & -3 & $-R \$ 90,00$ & $-R \$(112,80)$ & $R \$ 3.009,40$ \\
\hline 19 de Agosto & 3 & 4 & 3 & 15 & $\mathrm{R} \$ 450,00$ & $\mathrm{R} \$ 427,20$ & $\mathrm{R} \$ 3.436,60$ \\
\hline 20 de Agosto & 3 & 4 & 3 & 15 & $\mathrm{R} \$ 450,00$ & $\mathrm{R} \$ 427,20$ & $\mathrm{R} \$ 3.863,80$ \\
\hline 21 de Agosto & 4 & 8 & 4 & -6 & $-R \$ 240,00$ & $-\mathrm{R} \$(300,80)$ & $R \$ 3.563,00$ \\
\hline 22 de Agosto & 3 & 4 & 3 & 15 & $\mathrm{R} \$ 450,00$ & $\mathrm{R} \$ 427,20$ & $\mathrm{R} \$ 3.990,20$ \\
\hline 23 de Agosto & 4 & 4 & 4 & 12 & $\mathrm{R} \$ 480,00$ & $\mathrm{R} \$ 449,60$ & $\mathrm{R} \$ 4.439,80$ \\
\hline 26 de Agosto & 4 & 8 & 4 & 12 & $\mathrm{R} \$ 480,00$ & $\mathrm{R} \$ 419,20$ & $\mathrm{R} \$ 4.859,00$ \\
\hline 27 de Agosto & 4 & 9 & 4 & 6 & $\mathrm{R} \$ 240,00$ & $\mathrm{R} \$ 171,60$ & $R \$ 5.030,60$ \\
\hline 28 de Agosto & 4 & 12 & 4 & 0 & $\mathrm{R} \$-$ & $-\mathrm{R} \$(91,20)$ & $\mathrm{R} \$ 4.939,40$ \\
\hline 29 de Agosto & 4 & 5 & 4 & 12 & $\mathrm{R} \$ 480,00$ & $\mathrm{R} \$ 442,00$ & $\mathrm{R} \$ 5.381,40$ \\
\hline 30 de Agosto & 5 & 3 & 5 & -9 & $-R \$ 450,00$ & $-\mathrm{R} \$(478,50)$ & $\mathrm{R} \$ 4.902,90$ \\
\hline
\end{tabular}

Fonte: Autoria própria (2019)

No mês de setembro, já na primeira semana de operações avançou-se para a fase 5 e no dia 23 de setembro já se operava na fase 7 , encerrando assim, o período de aplicação da estratégia com um financeiro de $\mathrm{R} \$ 9.267,60$, uma 
rentabilidade sobre o capital inicial de $517,84 \%$. Ao todo foram 173 operações, sendo 80 operações no lucro, 63 operações no prejuízo e 30 operações zeradas.

Tabela 2 - Resultado estratégia mês de setembro

\begin{tabular}{|c|c|c|c|c|c|c|c|}
\hline Data & Fase & Operações & Contratos & Pontos & Resultado & Resultado Líq. & SALDO \\
\hline 02 de Setembro & 4 & 4 & 4 & 6 & $\mathrm{R} \$ 240,00$ & $\mathrm{R} \$ 179,60$ & $\mathrm{R} \$ 5.082,50$ \\
\hline 03 de Setembro & 4 & 3 & 4 & 3 & $\mathrm{R} \$ 120,00$ & $\mathrm{R} \$ 97,20$ & $\mathrm{R} \$ 5.179,70$ \\
\hline 04 de Setembro & 5 & 6 & 5 & 15 & $\mathrm{R} \$ 750,00$ & $R \$ 693,00$ & $\mathrm{R} \$ 5.872,70$ \\
\hline 05 de Setembro & 5 & 6 & 5 & 12 & $\mathrm{R} \$ 600,00$ & $\mathrm{R} \$ 543,00$ & $R \$ 6.415,70$ \\
\hline 06 de Setembro & 5 & 2 & 5 & 12 & $\mathrm{R} \$ 600,00$ & $\mathrm{R} \$ 581,00$ & $\mathrm{R} \$ 6.996,70$ \\
\hline 09 de Setembro & 6 & 5 & 6 & 6 & $\mathrm{R} \$ 360,00$ & $\mathrm{R} \$ 303,00$ & $\mathrm{R} \$ 7.299,70$ \\
\hline 10 de Setembro & 6 & 7 & 6 & 9 & $\mathrm{R} \$ 540,00$ & $R \$ 460,20$ & $\mathrm{R} \$ 7.759,90$ \\
\hline 11 de Setembro & 6 & 4 & 6 & 0 & $\mathrm{R} \$$ - & $-R \$ 45,60$ & $\mathrm{R} \$ 7.714,30$ \\
\hline 12 de Setembro & 6 & 7 & 6 & 12 & $\mathrm{R} \$ 720,00$ & $R \$ 640,20$ & $\mathrm{R} \$ 8.354,50$ \\
\hline 13 de Setembro & 6 & 1 & 6 & -3 & $-R \$ 180,00$ & $-R \$(191,40)$ & $\mathrm{R} \$ 8.163,10$ \\
\hline 16 de Setembro & 6 & 6 & 6 & 12 & $\mathrm{R} \$ 720,00$ & $\mathrm{R} \$ 651,60$ & $\mathrm{R} \$ 8.814,70$ \\
\hline 17 de Setembro & 6 & 2 & 6 & 12 & $\mathrm{R} \$ 720,00$ & $R \$ 697,20$ & $R \$ 9.511,90$ \\
\hline 18 de Setembro & 7 & 6 & 7 & 0 & $\mathrm{R} \$-$ & $-R \$(79,80)$ & $R \$ 9.432,10$ \\
\hline 19 de Setembro & 7 & 3 & 7 & -6 & $-R \$ 420,00$ & $-R \$ 459,90$ & $\mathrm{R} \$ 8.972,20$ \\
\hline 20 de Setembro & 6 & 1 & 6 & 6 & $\mathrm{R} \$ 360,00$ & $\mathrm{R} \$ 348,60$ & $\mathrm{R} \$ 9.320,80$ \\
\hline 23 de Setembro & 7 & 4 & 7 & 0 & $\mathrm{R} \$$ - & $-R \$(53,20)$ & $\mathrm{R} \$ 9.267,60$ \\
\hline
\end{tabular}

Fonte: Autoria própria (2019)

As cores vermelha e verde nas tabelas destacam os dias de mudança de fase, sendo a vermelha para retorno a uma fase anterior e a verde para o avanço de uma fase.

A estratégia e o modelo de manejo de posição carecem de mais testes e aplicações para validações cientificas baseadas em um método de natureza quantitativa, lançando mão de todos os rigores que tal método exige. Porém, a utilização de uma estratégia com expectativa matemática positiva, ou seja, quando se ganha, tem-se um resultado maior do que quando se perde, mostrouse inicialmente efetivo.

O aumento gradativo da posição em virtude do reinvestimento de ganhos, também se mostrou válido. Confirmou-se a percepção de Vince (2007) com relação a matemática de posição e a efetividade de seu modelo de flutuação das posições a medida que se avança ou se retorna nas fases.

Conclui-se que o presente estudo, mesmo com as limitações descritas acima, atingiu o objetivo inicialmente proposto e apresentou conceitos e parâmetros relevantes para o aprofundamento de futuras pesquisas dentro da área de derivativos e mercados futuros. 


\title{
Analysis of mini futures cambial contracts by exponential moving average with reinvestment of returns and balance of risks
}

\author{
ABSTRACT
}

The objective of this paper is to present an operational strategy to apply to future mini dollar contracts using the 21-period exponential moving average in the renko chart using return reinvestment and risk balancing techniques. Thus, it seeks to minimize the amount of capital initially invested, to benefit from the leverage offered by the dollar futures contract, to use risk management based on reinvestment of gains to maximize returns, while balancing the size of positions to minimize losses. When operations are impaired, that is, when the strategy does not perform well, the risk exposure decreases and when the strategy is performing, the position increases seeking greater returns.

Future Dollar. Futures Markets. Risk Management. 


\section{REFERÊNCIAS}

ADAM, Tim R. et al. Why do firms engage in selective hedging? Evidence from the gold mining industry. Journal of Banking and Finance, v.17, abril 2017, p. 269-288, 2017. crossref

BOLSA, T. (2019). Conheça o Gráfico Atemporal Renko. Disponível em: https://www.investimentonabolsa.com/2019/02/grafico-renko.html. Acesso em: 24 Set. 2019.

DOUGLAS, Mark. Trading - atitude mental do trade de sucesso. Mem Martins: Bookout.pt, 2015.

DEBASTIANI, Carlos Alberto. Candlestick: um método para ampliar lucros na bolsa de valores. São Paulo: Novatec Editora, 2007.

ELDER, Alexander. Aprenda a operar no mercado de ações. 11. ed. Rio de Janeiro: Elsevier, 2006. FAMA, E. \& BLUME, M. (1966). Filter rules and stock market trading profits. Journal of Business, 39:226-241. crossref

GARCIA, Márcio G. P. A macroeconomia do dólar futuro. Departamento de Economia, PUC - Rio, 1997.

GIL, Antônio Carlos. Métodos e técnicas de pesquisa social. 5. ed. São Paulo: Atlas, 2007.

KNECHTEL, Maria do Rosário. Metodologia da pesquisa em educação: uma abordagem teórico-prática dialogada. Curitiba: Intersaberes, 2014.

LIMA FILHO, Marcius Correia. Mercado de câmbio futuro no Brasil: Um estudo sobre o mercado de dólar futuro. 2017. 30 f. Monografia (Especialização) - Curso de Ciências Econômicas, Economia, Universidade de Brasília, Brasília, 2017.

LO, A., Mamaysky, H., \& Wang, J. (2000). Foundations of technical analysis: Computational algorithms, statistical inference, and empirical implementation. Journal of Finance, 55:1705-1765. crossref

NELOGICA (2019). Gráfico Renko. Disponível em:

https://www.nelogica.com.br/conhecimento/artigos/indicadores-estudo/graficorenko. Acesso em: 24 Set. 2019. 
NELOGICA (2019). O que é Análise Técnica? Disponível em:

https://www.nelogica.com.br/conhecimento/tutoriais/introtec/analise-tecnica. Acesso em: 24 Set. 2019.

RICHARDSON et al. Pesquisa social: métodos e técnicas. 3 ed. ver. ampl. São Paulo: Atlas 2007.

ROSSI, P. Especulação e arbitragem no mercado brasileiro de câmbio futuro. Revista de Economia Contemporânea, v. 18, no. 1, p. 84-99, 2014. crossref

ROSSI, Pedro. Política cambial no Brasil: um esquema analítico. Revista de Economia Política, v. 35, n. 4, p. 708-727, out/dez., 2015. SAFFI, Pedro A. C.. Análise Técnica: Sorte ou Realidade?. Rbe, Rio de Janeiro, v. 4, n. 57, p.953-974, out. 2003. crossref

SILVA, Edna Lúcia da; MENEZES, Estera Muskat. Metodologia da pesquisa e elaboração de dissertação. 3. ed. rev. e atual. Florianópolis: Laboratório de Ensino à Distância da UFSC, 2001.

SWEENEY, R. (1988). Some new filter rule tests: Methods and results. Journal of Financial and Quantitative Analysis, 23:285-300. crossref

VINCE, Ralph. The Handbook of Portfolio Mathematics: formulas for optimal allocation \& leverage. New Jersey: Jonh Wiley \& Sons, Inc, 2007.

WOLWACZ, Alexandre. Setups baseados em médias móveis. Porto Alegre: Leandro \& Stormer, 2010.

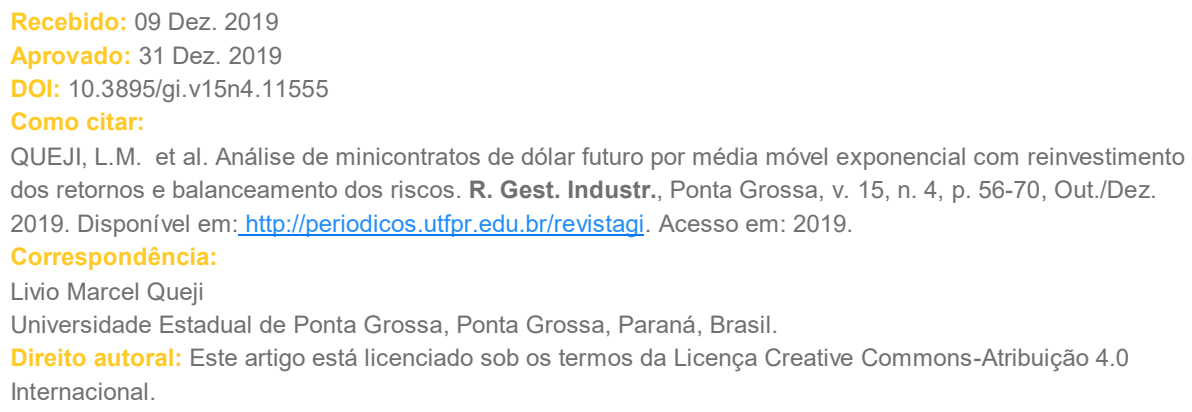

QUEJI, L.M. et al. Análise de minicontratos de dólar futuro por média móvel exponencial com reinvestimento dos retornos e balanceamento dos riscos. R. Gest. Industr., Ponta Grossa, v. 15, n. 4, p. 56-70, Out./Dez. 2019. Disponível em: http://periodicos.utfpr.edu.br/revistagi. Acesso em: 2019. 